\title{
Tailoring of Nanoscale Porosity in Carbide-Derived Carbons for Efficient Hydrogen Storage
}

\author{
Yury Gogotsi ${ }^{1 *}$, Ranjan K. Dash ${ }^{1}$, Gleb Yushin ${ }^{1}$, Taner Yildirim² ${ }^{2}$, Giovanna Laudisio ${ }^{3}$ \& John E. Fischer ${ }^{3}$ \\ ${ }^{I}$ Department of Materials Science and Engineering and A.J. Drexel Nanotechnology Institute, Drexel University, \\ Philadelphia, PA, 19104, USA. ${ }^{2}$ National Institute of Standards and Technology, Gaithersburg, MD 20899, USA. \\ ${ }^{3}$ Department of Materials Science and Engineering, University of Pennsylvania, Philadelphia, PA, 19104, USA.
}

\section{METHODS}

Materials. The experimental setup and structure/composition of carbide powders for synthesis of CDC have been described elsewhere. ${ }^{1}$ While many CDCs have been studied, providing a large volume of statistically reliable data, only data for CDC produced from boron carbide $\left(\mathrm{B}_{4} \mathrm{C}\right)$, titanium carbide $(\mathrm{TiC})$, zirconium carbide $(\mathrm{ZrC})$ and silicon carbide $(\beta-\mathrm{SiC})$ are referred to in this work. The particle sizes of the powders were $6 \mu \mathrm{m}, 2 \mu \mathrm{m}, 8 \mu \mathrm{m}$ and $0.7 \mu \mathrm{m}$, respectively. The synthesis of CDC from these carbides was described in our previous publications. ${ }^{1,2}$ The starting material was placed into the quartz tube of a resistance furnace in a quartz boat. The furnace was then heated to the desired temperature $\left(400-1200^{\circ} \mathrm{C}\right)$ under argon (BOC Gases, 99.998\%) purge. Once the desired reaction temperature was reached, chlorine gas (BOC Gases, 99.5\%) at 10-15 $\mathrm{cm}^{3} / \mathrm{min}$ was passed through the tube furnace for $3 \mathrm{hours}$. After chlorination, the furnace was cooled to room temperature under argon purge. Hydrogen annealing was done using the same furnace at $600^{\circ} \mathrm{C}$ for $2 \mathrm{~h}$. As shown by PGAA, chlorine trapped during the synthesis was a major contamination in the sample but its content decreases well below 1 at $\%$ after hydrogen treatment. Carbide forming metals may eventually be present in incompletely chlorinated samples, but their content in the TiC-CDC samples used to generate data of Fig. 3 was $\sim 0.05$ at. $\%$.

Several other materials have been studied for comparison and independent verification of the results for CDC reported here. These include SWCNT from Rice University (TUBES@RICE) and open ended nanotubes from NanoCarbLab, Moscow (http://www.nanocarblab.com). According to the manufacturer, the latter sample was purified and activated by combination of acid treatment $\left(\mathrm{HCl}\right.$ and $\left.\mathrm{HNO}_{3}\right)$ and thermal oxidation in air flow. At the end, nanotubes were washed in water and dried in air flow at $140^{\circ} \mathrm{C}$. Neutron powder diffraction performed at NIST indicated some graphite and nickel in that sample. Both of these SWNT materials stored less hydrogen than arc-discharge produced nanotubes oxidized at $350^{\circ} \mathrm{C}$ and containing metal oxide ${ }^{3}$, so we report the latter in Fig. $3 \mathrm{~b}$ as the best reliable result for SWCNT available to us. The MWCNT (10-20 nm diameter) reported in Fig. 3b come from Arkema, France, and were produced by a catalytic CVD technique. Deuturated MOF-5 samples with the molecular formula $Z_{n} \mathrm{O}_{13} \mathrm{C}_{24} \mathrm{D}_{12}$ were produced at NIST. Their structure and composition were confirmed by neutron scattering. The result that we obtained (Fig. $3 \mathrm{a}, 1.25 \mathrm{wt} . \%$ of $\left.\mathrm{H}_{2}\right)$ is in good agreement with 1.3 wt.\% reported for MOF-5 by Yaghi's group. ${ }^{4}$

Sorption analysis. Quantachrome Autosorb-1 was used for sorption analysis with argon as adsorbate at $77 \mathrm{~K}$ as reported previously. ${ }^{2}$ The SSA of the carbon material was calculated according to BET (Brunauer, Emmet, Teller) equation ${ }^{5}$ and pore volume was calculated from argon adsorption using nonlocal density functional theory (NLDFT). ${ }^{29}$ Weighted pore size of the carbons was defined as

$$
\frac{\sum_{i=1}^{n} d_{i} \cdot v_{i}}{\sum_{i=1}^{n} v_{i}} \text {, where } d \text { is pore size and } v \text { is pore volume. Gravimetric density of hydrogen (wt.\%) was defined as }
$$

$\left(\rho_{\text {Hydrogen }} \cdot v_{\text {Hydrogen }} .100\right)$, where $\rho_{\text {Hydrogen }}$ is the hydrogen density in $\mathrm{g} / \mathrm{cm}^{3} ; v_{\text {Hydrogen }}$ is the volume of hydrogen adsorbed at $\sim 760$ $\mathrm{mm}$ of $\mathrm{Hg}$ per unit mass of $\mathrm{CDC}$, in $\mathrm{cm}^{3} / \mathrm{g}$. Results of all measurements have been summarized in Supplement 1.

Hydrogen sorption isotherms were collected using Quantachrome Autosorb-1 at 77K as described in Quantachrome's technotes. ${ }^{6}$ This technique has been widely used to study hydrogen sorption on a variety of carbons, including activated carbons ${ }^{7}$ and nanotubes ${ }^{3}$, and it enables comparison with literature data. Its advantage is in recording the full sorption/desorption cycle, which decreases possibility of error and shows if any irreversible sorption occurs. The gravimetric and volumetric densities of stored hydrogen were based on sample mass after degassing at $300^{\circ} \mathrm{C}$ in vacuum and on the calculated specific weight of CDC derived from carbides. Independent measurements were conducted on selected samples at Quantachrome's laboratory to validate those performed at Drexel University. These were conducted on TiC- and ZrC-CDC using Autosorb-1 and Nova instruments and demonstrated excellent agreement with our data reported in this article. This also allows us to comfortably compare our results with those reported for SWCNT in ref. ${ }^{3}$ authored by Quantachrome researchers (see Fig. 3b). Sieverts apparatus measurements were also performed at NIST to compare CDC with SWCNT and MOF-5 samples.

\section{References:}

(1) Dash, R. K.; Nikitin, A.; Gogotsi, Y., Microporous and Mesoporous Materials 2004, 72, 203-208

(2) Dash, R. K.; Yushin, G.; Gogotsi, Y., Microporous and Mesoporous Materials in press, 2005.

(3) Anson, A.; Callejas, M. A.; Benito, A. M.; Maser, W. K.; Izquierdo, M. T.; Rubio, B.; Jagiello, J.; Thommes, M.; Parra, J. B.; Martınez, M. T., Carbon 2004, 42, $1243-1248$

(4) Rowsell, J.; Millward, A.; Park, K.; Yaghi, O. M., J. Am. Chem. Soc. 2004, 126, 5666-5667.

(5) Brunauer, S.; Emmett, P.; Teller, E., J. Am. Chem. Soc. 1938, 60, 309-319.

(6) Powder Technote 37, Quantachrome Corporation, 1900 Corporate Drive, Boynton Beach, FL 33426 USA, < http://www.quantachrome.com >.

(7) Jagiello, J.; Thommes, M., Carbon 2004, 42, 1227-1232. 
Supplement 1. CDC synthesis conditions and results of sorption measurements.

\begin{tabular}{|c|c|c|c|c|c|c|}
\hline \multicolumn{2}{|c|}{ Synthesis conditions } & \multicolumn{3}{|c|}{$\begin{array}{l}\text { Analysis of } 77 \mathrm{~K} \text { argon sorption } \\
\text { isotherms }\end{array}$} & \multirow{2}{*}{$\begin{array}{l}\text { Hydrogen } \\
\text { uptake at } 77 \mathrm{~K}, 1 \\
\text { atm pressure, } \\
\text { cc/g }(\mathrm{wt} \%)\end{array}$} & \multirow{2}{*}{$\begin{array}{l}\text { Hydrogen uptake } \\
\text { per SSA, } \\
\frac{w t \% \cdot g}{m^{2}} \cdot 10^{3}\end{array}$} \\
\hline $\begin{array}{l}\text { Metal } \\
\text { carbide }\end{array}$ & $\begin{array}{l}\text { Chlorination } \\
\text { temperature, } \\
{ }^{\circ} \mathrm{C}\end{array}$ & $\begin{array}{l}\mathrm{BET} \\
\mathrm{SSA}, \\
\mathrm{m}^{2} / \mathrm{g}\end{array}$ & $\begin{array}{l}\text { Pore } \\
\text { size, } \\
\text { nm }\end{array}$ & $\begin{array}{l}\text { Pore } \\
\text { volume, } \\
\mathrm{cc} / \mathrm{g}\end{array}$ & & \\
\hline $\mathrm{TiC}$ & 400 & 1199 & 0.74 & 0.54 & $179(1.61)$ & 1.34 \\
\hline $\mathrm{TiC}$ & 600 & 1058 & 0.67 & 0.47 & $255(2.29)$ & 2.17 \\
\hline $\mathrm{TiC}$ & 800 & 1566 & 0.92 & 0.82 & $284(2.55)$ & 1.63 \\
\hline $\mathrm{TiC}$ & 1200 & 1714 & 1.42 & 0.93 & $171(1.54)$ & 0.90 \\
\hline $\mathrm{TiC}$ & $400 *$ & 1113 & 0.68 & 0.51 & $269(2.42)$ & 2.17 \\
\hline $\mathrm{TiC}$ & $800^{*}$ & 1943 & 1.00 & 0.94 & $336(3.02)$ & 1.55 \\
\hline $\mathrm{ZrC}$ & 400 & 494 & 0.75 & 0.23 & $125(1.12)$ & 2.27 \\
\hline $\mathrm{ZrC}$ & 600 & 859 & 0.80 & 0.48 & $180(1.62)$ & 1.88 \\
\hline $\mathrm{ZrC}$ & 800 & 1342 & 0.83 & 0.61 & $214(1.92)$ & 1.43 \\
\hline $\mathrm{ZrC}$ & 1000 & 1499 & 1.21 & 0.72 & $207(1.86)$ & 1.24 \\
\hline $\mathrm{ZrC}$ & 1200 & 1857 & 1.41 & 0.91 & $220(1.98)$ & 1.07 \\
\hline $\mathrm{ZrC}$ & $400 *$ & 1073 & 0.72 & 0.51 & $217(1.95)$ & 1.82 \\
\hline $\mathrm{ZrC}$ & $600 *$ & 1388 & 0.97 & 0.65 & $287(2.58)$ & 1.86 \\
\hline $\mathrm{ZrC}$ & $800^{*}$ & 1741 & 1.17 & 0.78 & $272(2.45)$ & 1.40 \\
\hline $\mathrm{ZrC}$ & $1000 *$ & 1926 & 1.18 & 0.90 & $273(2.45)$ & 1.27 \\
\hline $\mathrm{B}_{4} \mathrm{C}$ & 600 & 1165 & 1.04 & 0.58 & $164(1.47)$ & 1.27 \\
\hline $\mathrm{B}_{4} \mathrm{C}$ & 750 & 1815 & & & $207(1.86)$ & 1.03 \\
\hline $\mathrm{B}_{4} \mathrm{C}$ & 800 & 2012 & 0.97 & 0.99 & $213(1.91)$ & 0.95 \\
\hline $\mathrm{B}_{4} \mathrm{C}$ & 1000 & 1857 & & & $196(1.76)$ & 0.95 \\
\hline $\mathrm{B}_{4} \mathrm{C}$ & 1200 & 1520 & 1.43 & 0.87 & $145(1.30)$ & 0.86 \\
\hline $\mathrm{SiC}$ & 1100 & 1424 & 0.86 & 0.53 & $212(1.91)$ & 1.34 \\
\hline $\mathrm{SiC}$ & 1200 & 1279 & 0.97 & 0.49 & $234(2.10)$ & 1.84 \\
\hline
\end{tabular}

*Samples were hydrogen annealed at $600^{\circ} \mathrm{C}$ for $2 \mathrm{~h}$. 


\title{
Synthesis, structure and porosity analysis of microporous and mesoporous carbon derived from zirconium carbide
}

\author{
R.K. Dash *, G. Yushin, Y. Gogotsi \\ Drexel University, Department of Material Science and Engineering and A.J. Drexel Nanotechnology Institute, \\ 3141 Chestnut Street, Philadelphia, PA 19104, USA
}

Received 20 January 2005; received in revised form 18 May 2005; accepted 31 May 2005

\section{Introduction}

Highly porous carbons are in great demand because of their potential applications in gas storage, molecular sieves, catalyses, absorbents, electrodes in batteries and supercapacitors, water/air filters and medical devices [1]. For efficient application, a certain pore size distribution (PSD) is required in each case. Most porous carbons are produced through pyrolysis and activation of organic carbonaceous materials. However, this process does not allow the needed fine-tuning of the pore structure. Alternatively, carbons can be produced by extrac-

\footnotetext{
* Corresponding author. Tel.: +1 2672306863; fax: +1 2158951934 E-mail address: rkd25@drexel.edu (R.K. Dash).
}

tion of metals from carbides. Such carbons are called carbide derived carbons (CDCs) [2]. Their structure and pore size can be tuned by choosing the appropriate synthesis conditions and the initial carbide $[3,4]$. In particular, it has been shown that PSD and specific surface area (SSA) of CDC derived from $\mathrm{Ti}_{3} \mathrm{SiC}_{2}[3]$ and $\mathrm{B}_{4} \mathrm{C}$ [4] depend on the synthesis temperature. However, the effect of temperature on porous structure of CDC derived from other carbides has not been reported in literature.

Zirconium carbide is a commercially available transition metal carbide characterized by high hardness, high strength and high melting point. It has a face centered cubic (fcc) crystal structure (space group Fm3m) with a lattice parameter of $0.4698 \mathrm{~nm}$ and density of 6.59 
$51 \mathrm{~g} / \mathrm{cc}$. Zirconium carbide is a non-stoichiometric carbide 52 and its composition ranges from $\mathrm{ZrC}_{0.55}$ to $\mathrm{ZrC}_{0.99}$ [5]. 53 As zirconium carbide crystallizes in a rock salt structure, 54 with each zirconium atom surrounded by six carbon 55 atoms at a distance of $0.2349 \mathrm{~nm}$, the CDC produced 56 at low temperature, where little structural rearrange57 ment is allowed, is expected to have uniformly distrib58 uted small pores, similar to SiC-derived carbon [6]. 59 Assuming the CDC reaction to be conformal (no shrink60 age after metal extraction), simple theoretical calcula61 tion [2] shows that the $\mathrm{ZrC}-\mathrm{CDC}$ should have a pore 62 volume of $0.86 \mathrm{cc} / \mathrm{g}(66 \%)$ and a pore size of $\sim 0.5 \mathrm{~nm}$.

In this paper, we performed a systematic study of the effect of synthesis temperature on the structure and porosity of CDC synthesized from zirconium carbide (we will call it $\mathrm{ZrC}-\mathrm{CDC}$ ). Although formation of carbon upon chlorination of $\mathrm{ZrC}$ has already been reported in literature [7], little information is available on its PSD, and the effect of chlorination temperature on the porosity and structure of the resultant carbon.

\section{2. Experimental}

Zirconium carbide powder of chemical formula $\mathrm{ZrC}_{0.98}$ was obtained from H.C. Stark. The starting material with the average particle size $8 \mu \mathrm{m}$ contained $0.1 \%$ of free carbon with traces of oxygen, nitrogen, iron and hafnium.

The experimental setup for CDC synthesis was described elsewhere [2,4]. For etching of $\mathrm{Zr}$ from $\mathrm{ZrC}_{0.98}$, the sample in a quartz boat was placed in a quartz tube furnace and heated to the desired temperature (200$1200{ }^{\circ} \mathrm{C}$ ) under an argon (BOC Gases, 99.998\%) purge. Once the desired temperature was reached, chlorine gas (BOC Gases, $99.5 \%$ ) at a velocity of $10-15 \mathrm{~cm}^{3} / \mathrm{min}$ was passed through the tube furnace (diameter $=1 \mathrm{in}$.) of tube furnace for $3 \mathrm{~h}$. After the chlorination, the furnace was cooled down to room temperature under an argon purge.

Thermodynamic simulation was done using ChemSage v4.14 GTT advanced SOLGASMIX-based Gibbs energy minimization program. XRD analysis was done using a Rigaku diffractometer with $\mathrm{CuK}_{\alpha}$ radiation $(\lambda=0.154 \mathrm{~nm})$ operated at $30 \mathrm{~mA}$ and $40 \mathrm{kV}$. XRD patterns were collected using step scans, with a step size of $0.05^{\circ}(2 \theta)$ and a count time of $2 \mathrm{~s}$ per step between 10 and $60(2 \theta)$. Samples were also analyzed by micro-Raman spectroscopy (Renishaw 1000) using an Ar ion laser $(514.5 \mathrm{~nm})$ at $500 \times$ magnification $(\sim 2 \mu \mathrm{m}$ spot size $)$. Deconvolution of the Raman spectra was done by using two bands: the D band and the $G$ band of graphite with the peak fitting application provided by GRAMS software which uses an iterative fitting of Gaussian and Lorentzian functions with the data minimized by the chi-squared criterion. TEM samples were prepared by dispersing the sample in isopropyl alcohol over a copper grid with a lacey carbon film, TEM study was performed using JEOL 2010F microscope at $200 \mathrm{kV}$.

Sorption analysis of the porous carbon was done using Ar as adsorbate at $-195.8^{\circ} \mathrm{C}$ with Quantachrome Autosorb-1. The samples were degassed overnight under vacuum at $300{ }^{\circ} \mathrm{C}$ and backfilled with helium gas before the sorption measurement. The SSA of the porous carbon material was calculated for Ar sorption according to the BET (Brunauer, Emmet, Teller) equation [8-10]. PSDs and pore volume for $\mathrm{Ar}$ adsorption were calculated using the non-local density functional theory (NLDFT) method provided by Quantachrome's data reduction software (version 1.27) and developed by Neimark and co-workers [11].

\section{Results}

\subsection{Thermodynamic simulation}

Thermodynamic analysis of interaction between $\mathrm{ZrC}$ and $\mathrm{Cl}_{2}$ was performed to understand the effect of temperature and chlorine amount in the system on the carbon formation. Fig. 1 shows thermodynamic simulation for the reaction of $1 \mathrm{~mol}$ of $\mathrm{ZrC}$ with $3 \mathrm{~mol}$ (Fig. 1a), $4 \mathrm{~mol}$ (Fig. 1b) and $5 \mathrm{~mol}$ (Fig. 1c) of $\mathrm{Cl}_{2}$ in the temperature range of $0-1200{ }^{\circ} \mathrm{C}$ at a step of $50{ }^{\circ} \mathrm{C}$. The calculations were performed for a closed system with a total constant pressure of $1 \mathrm{~atm}$. The simulations resulted in three chemical equations for three different temperature ranges.

Range I: In this low temperature range, no CDC synthesis is thermodynamically possible under equilibrium conditions due to the preferential formation of $\mathrm{CCl}_{4}$ over solid $\mathrm{C}$, as shown in following reaction:

$\mathrm{ZrC}_{(\mathrm{s})}+4 \mathrm{Cl}_{2(\mathrm{~g})} \rightarrow \mathrm{ZrCl}_{4(\mathrm{~s}, \mathrm{~g})}+\mathrm{CCl}_{4(\mathrm{~s}, \mathrm{~g})}$

Range II: In this mid temperature range, CDC forms and its amount increases with temperature. However, the carbon yield is still limited by the formation of $\mathrm{CCl}_{4}$.

$\mathrm{ZrC}_{(\mathrm{s})}+3 \mathrm{Cl}_{2(\mathrm{~g})} \rightarrow \mathrm{ZrCl}_{4(\mathrm{~s}, \mathrm{~g})}+0.5 \mathrm{C}_{(\mathrm{s})}+0.5 \mathrm{CCl}_{4(\mathrm{~s}, \mathrm{~g})}$

Range III: In this high temperature range, there is no formation of $\mathrm{CCl}_{4(\mathrm{~s}, \mathrm{~g})}$ and thus there is no loss of carbon as $\mathrm{CCl}_{4(\mathrm{~s}, \mathrm{~g})}$ which results in the formation of $1 \mathrm{~mol}$ of carbon per mol of carbide.

$\mathrm{ZrC}_{(\mathrm{s})}+2 \mathrm{Cl}_{2(\mathrm{~g})} \rightarrow \mathrm{ZrCl}_{4(\mathrm{~g})}+\mathrm{C}_{(\mathrm{s})}$

The temperature limits of each range depend on the amount of $\mathrm{Cl}_{2}$ used in the calculation. Range II, for example, changed from $\sim 0-600{ }^{\circ} \mathrm{C}$ to $\sim 250-700{ }^{\circ} \mathrm{C}$ and to $\sim 350-750^{\circ} \mathrm{C}$ when the amount of $\mathrm{Cl}_{2}$ changed 
R.K. Dash et al. I Microporous and Mesoporous Materials xxx (2005) xxx-xxx
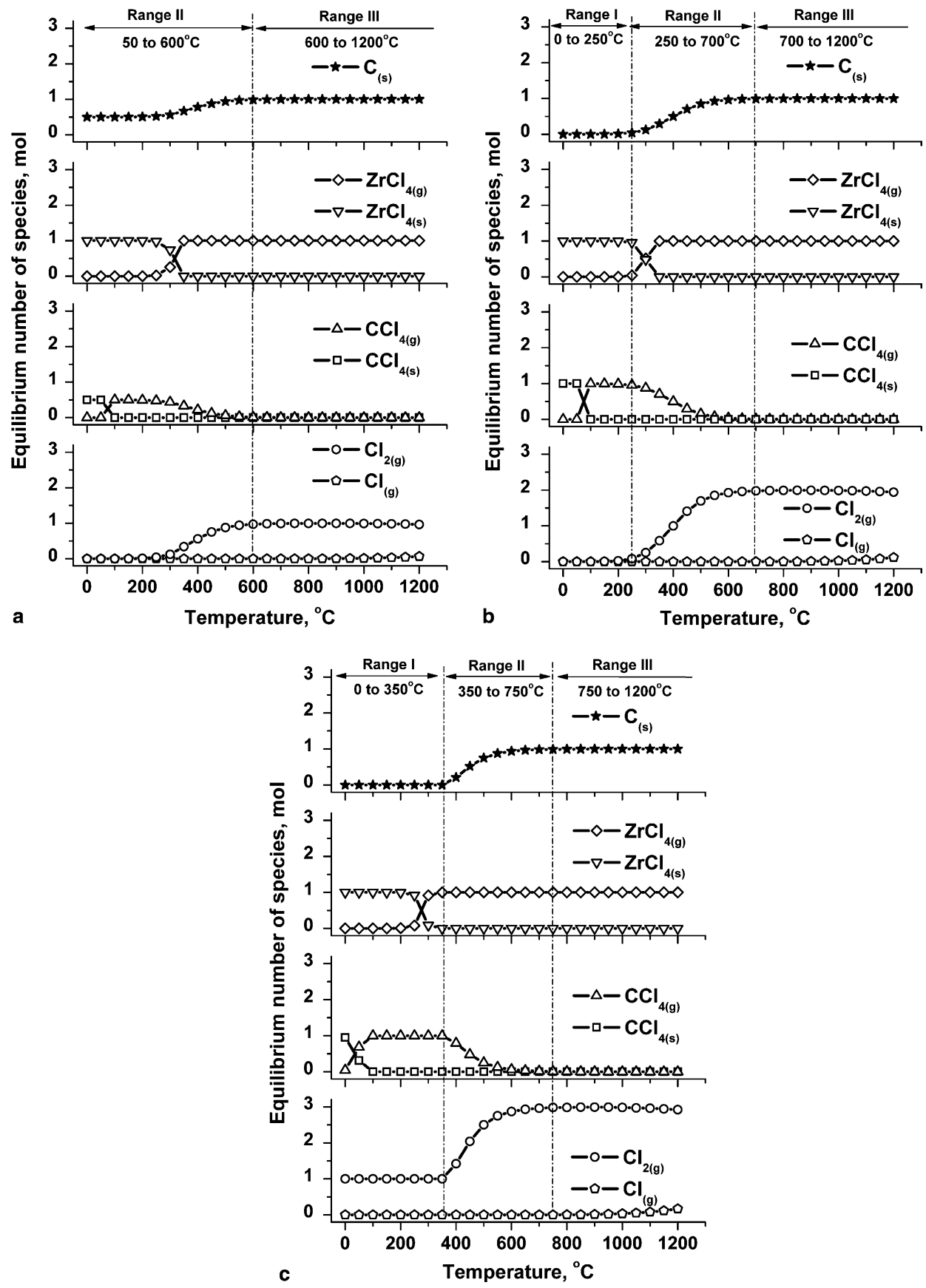

Fig. 1. Equilibrium reaction products as a function of chlorination temperature for $1 \mathrm{~mol}$ of $\mathrm{ZrC}$ and with (a) $3 \mathrm{~mol}$, (b) $4 \mathrm{~mol}$ and (c) $5 \mathrm{~mol}$ of $\mathrm{Cl}_{2}$.

153 from 3 to 4 and to $5 \mathrm{~mol}$, respectively, while the amount 154 of $\mathrm{ZrC}$ was kept constant $(1 \mathrm{~mol})$. Thus, decreasing 155 chlorine concentration favors formation of carbon, 156 while excess chlorine may etch carbon, eventually lead157 ing to a lower yield and/or larger pore size.

158 As the chlorination experiments were performed in 159 an open environment, the results of the performed sim160 ulations provided only general guidelines for the exper-

161 imental design and were not expected to give precise 162 quantitative information.

\subsection{Powder XRD}

$\mathrm{XRD}$ analysis was carried out on powder samples to investigate the structural changes in $\mathrm{ZrC}-\mathrm{CDC}$ that occurred at different chlorination temperatures. The XRD patterns (Fig. 2) of CDC produced at $200{ }^{\circ} \mathrm{C}$ showed peaks of $\mathrm{ZrC}$, suggesting the incomplete conversion of $\mathrm{ZrC}$ to $\mathrm{CDC}$. At temperatures of $300{ }^{\circ} \mathrm{C}$ and above, only two peaks, corresponding to the $(002)$ and $(004)$ planes of graphite were seen. The large width 


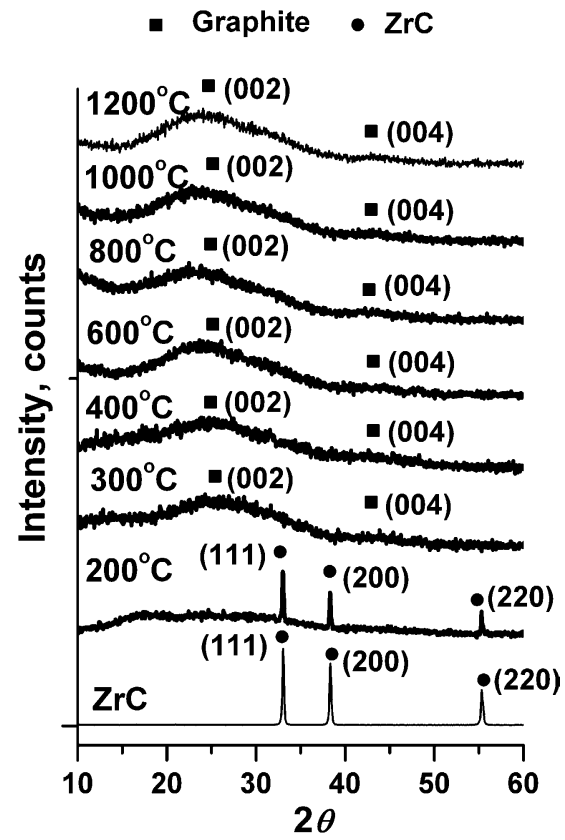

Fig. 2. XRD of untreated $\mathrm{ZrC}$ and samples chlorinated at different temperatures.

172 of these peaks suggested a disordered structure of the

$173 \mathrm{CDC}$ formed in this temperature range. As temperature

174 increased from 300 to $1200{ }^{\circ} \mathrm{C}$, the peak became more

175 narrow indicating ordering of carbon.

\section{3.3. Raman spectroscopy analysis}

The first-order Raman spectra of perfectly ordered graphite only show one peak at $1582 \mathrm{~cm}^{-1}$, whereas the disordered carbon generally demonstrates two peaks: the graphite (G) peak at $\sim 1582 \mathrm{~cm}^{-1}$ and the disorder-induced (D) peak at $\sim 1350 \mathrm{~cm}^{-1}[12,13]$. Another disorder-induced peak (the $\mathrm{D}^{\prime}$ peak) located at $\sim 1600$ $1620 \mathrm{~cm}^{-1}[12,13]$ is often superimposed with the broad $\mathrm{G}$ peak in disordered carbons and thus is not considered separately. $G$ peak corresponds to in-plane stretching of graphite $[14,15]$ whereas the D-peak is generally associated with a double-resonance Raman process in disordered carbon [16]. The $\mathrm{D}^{\prime}$-peak corresponds to a strong maximum in the vibrational density of states (VDOS) of graphite [12].

Raman spectra of the as-received zirconium carbide sample showed very weak $D$ and $G$ bands indicating traces of free carbon. As the temperature of synthesis increased from 200 to $1200{ }^{\circ} \mathrm{C}, \mathrm{CDC}$ becomes more ordered as evident by a decrease in full width at half maximum (FWHM) values of the D-band and G-band of graphite (Figs. 3 and $4 \mathrm{a}$ ). At $1200^{\circ} \mathrm{C}$, the FWHM of $\mathrm{D}$ and $\mathrm{G}$ bands were $\sim 80$ and $90 \mathrm{~cm}^{-1}$ which is about 5 times the value of graphite single crystal. As in most CDCs [3,17], the ratio of the integrated intensities of $\mathrm{D}$ and $\mathrm{G}$ bands $\left(I_{\mathrm{D}} / I_{\mathrm{G}}\right)$ decreases with synthesis temper-

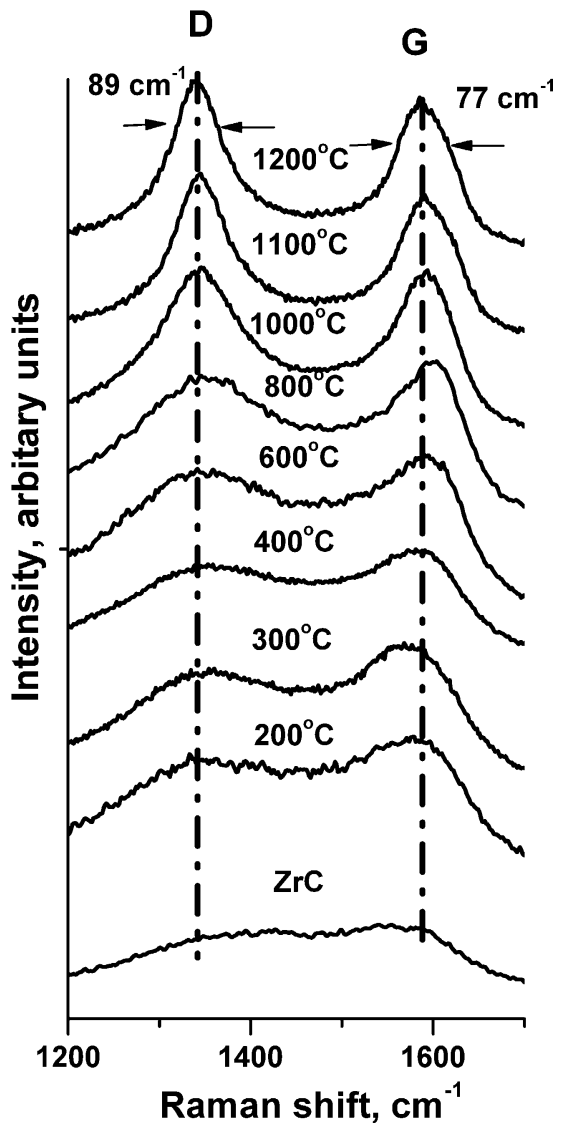

Fig. 3. Raman spectra of untreated $\mathrm{ZrC}$ and samples chlorinated at different temperatures.

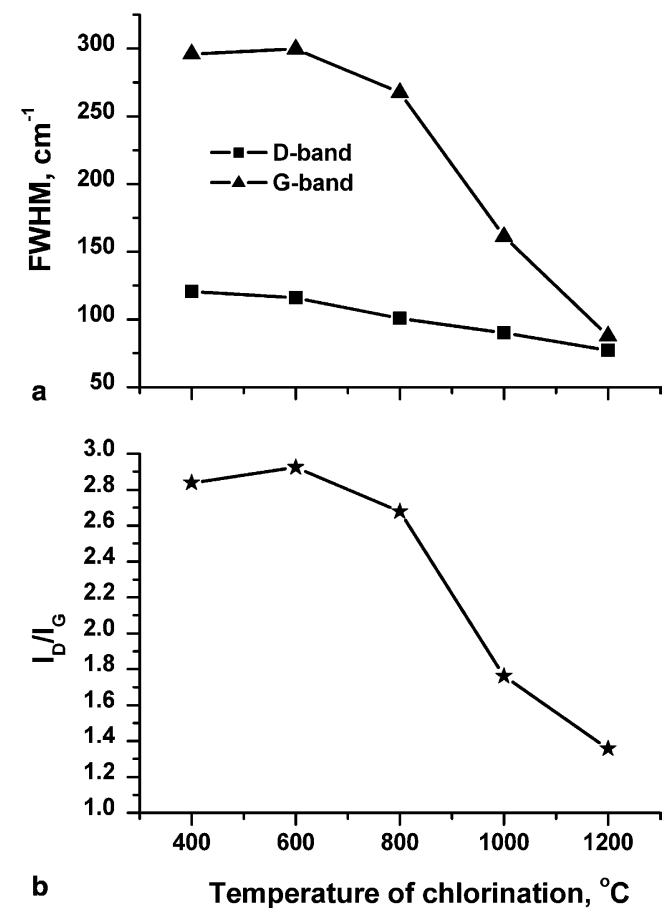

Fig. 4. Raman analysis of ZrC-CDC. (a) FWHM of D and G bands and (b) $I_{\mathrm{D}} / I_{\mathrm{G}}$ ratio for different temperatures of chlorination. 
202 ature, which is probably due to the formation of planar 203 graphite at high temperature (Fig. 4b).

\section{3.4. TEM analysis}

205 In agreement with XRD and Raman spectroscopy, 206 TEM revealed an increase in the degree of ordering in 207 the $\mathrm{CDC}$ with chlorination temperature. At $300^{\circ} \mathrm{C}$, 208 the $\mathrm{CDC}$ produced consisted of amorphous carbon 209 (Fig. 5a). At $800^{\circ} \mathrm{C}$, along with the presence of amor210 phous carbon, the formation of thin graphitic ribbons 211 (Fig. 5b) was seen. At $1200^{\circ} \mathrm{C}$ (Fig. 5c), CDC contained 212 less amorphous carbon and more ordered curved sheets
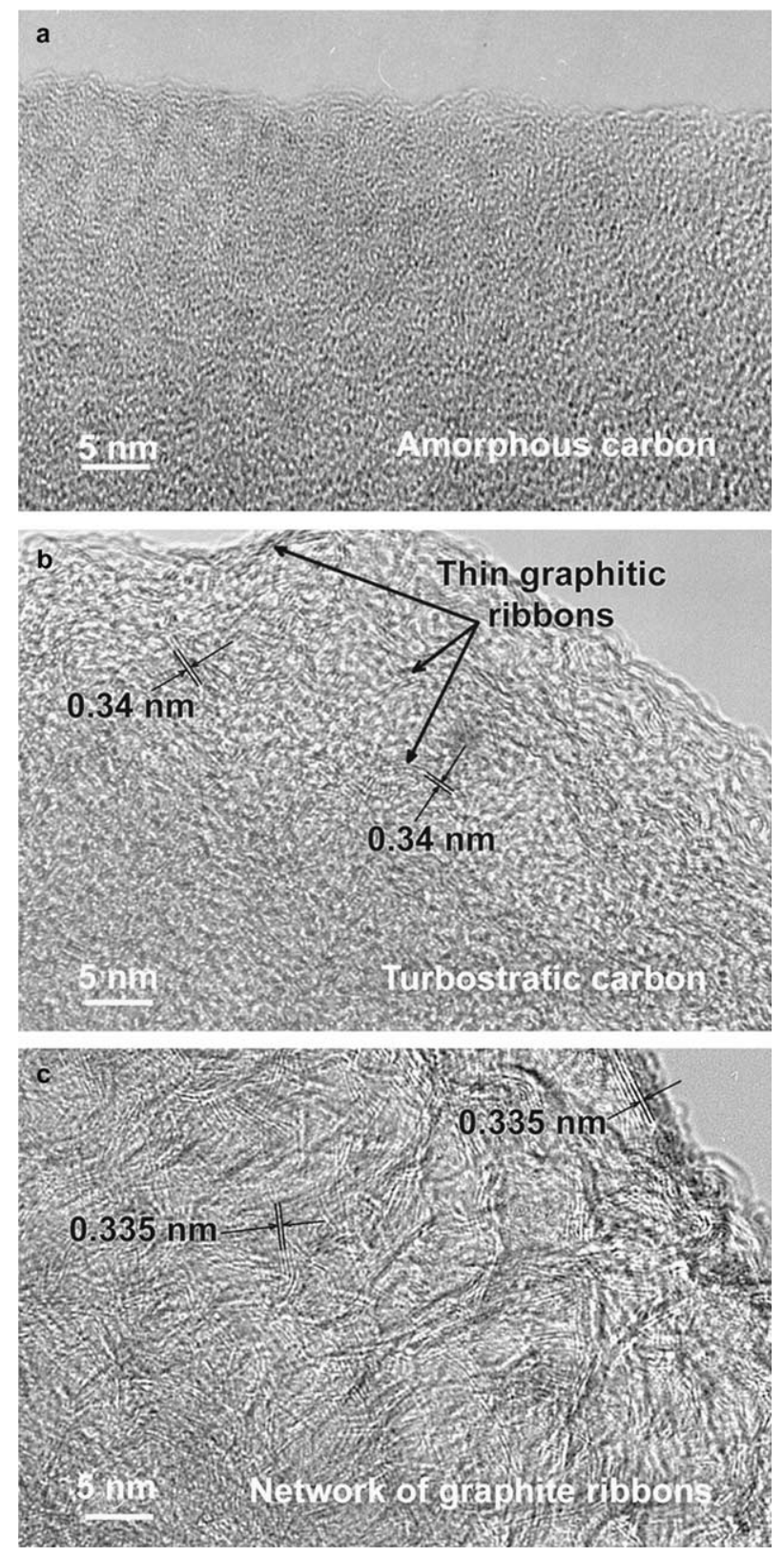

Fig. 5. TEM images of $\mathrm{CDC}$ produced from $\mathrm{ZrC}$ at temperatures of (a) $300{ }^{\circ} \mathrm{C}$, (b) $800^{\circ} \mathrm{C}$ and (c) $1200{ }^{\circ} \mathrm{C}$. of graphite with an interplanar distance of $\sim 0.34 \mathrm{~nm}$, which is slightly higher than the interplanar spacing of $(0002)$ planes of graphite $(0.335 \mathrm{~nm})$. The average thickness of graphite ribbons was less than $1 \mathrm{~nm}$. It was noticed however, that the edges of the CDC particles contain thicker ribbons.

At low chlorination temperatures, the diffusion of carbon atoms is extremely slow and they are only slightly displaced from their original positions in the $\mathrm{ZrC}$ lattice, leading to the amorphous structure. As synthesis temperature increased, the diffusion rate of carbon atoms increased allowing them to arrange themselves in more ordered carbon structures. The diffusion of surface carbon atoms is easier and thus the formation of graphite layer will first take place at the surface of $\mathrm{ZrC}$ grains. It is also important that since extraction starts from the surface, the surface carbon atoms may experience rearrangement due to diffusion and gas phase transport while the reaction propagates towards the center of the particle.
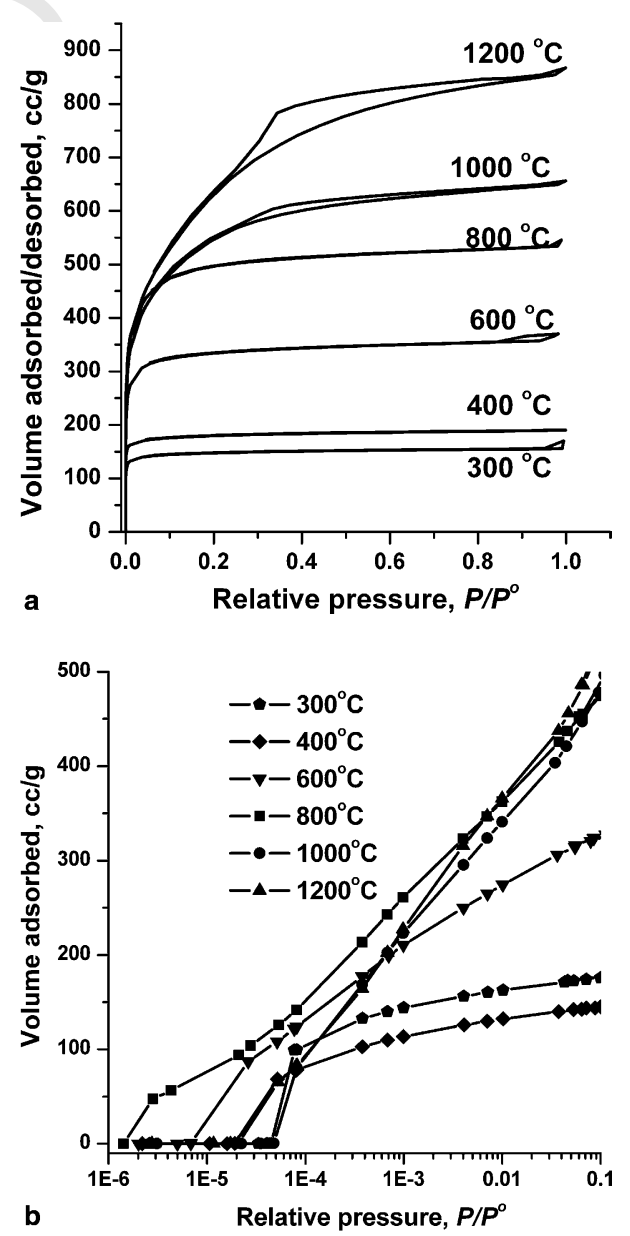

Fig. 6. Argon adsorption and desorption isotherm at $-195.8^{\circ} \mathrm{C}$ of $\mathrm{CDC}$ derived from $\mathrm{ZrC}$ at different temperatures: (a) whole isotherm at a linear relative pressure scale; (b) semilogarithmic scale plot showing the low pressure part of the diagram in (a). 


\subsection{Argon sorption analysis}

Porosity analysis was carried out on samples chlorinated at $300,400,600,800,1000$ and $1200{ }^{\circ} \mathrm{C}$ using of Ar as the absorbate and liquid nitrogen as the coolant. The SSAs of the completely converted CDC samples were calculated using the BET equation for volume of gas adsorbed at relative pressures between 0.05 and 0.3 , where the BET isotherm is linear. Isotherms of
300-800 ${ }^{\circ} \mathrm{C}$ samples (Fig. 6a) belong to type-I [18] of the Brunauer classifications [19], which is a characteristic of microporous materials (pore size less than $2 \mathrm{~nm}$ according to IUPAC classification). A small hysterisis loop in the adsorption-desorption isotherm of the $1000{ }^{\circ} \mathrm{C}$ sample was seen between a relative pressure of 0.3 and 0.9 . This hysterisis loop significantly widened for the sample synthesized at $1200^{\circ} \mathrm{C}$.

a

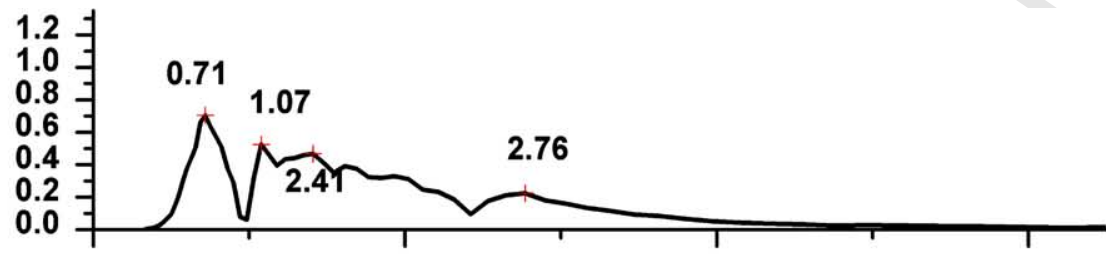

b
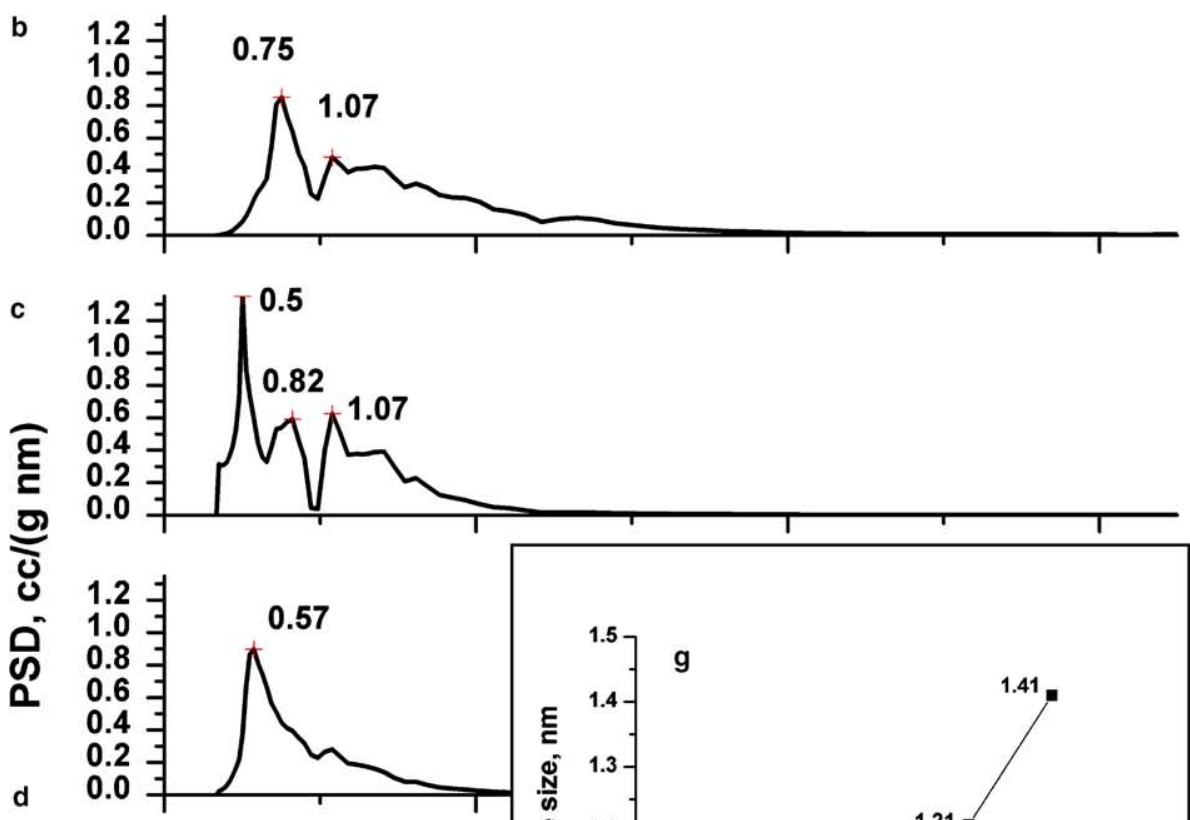

d

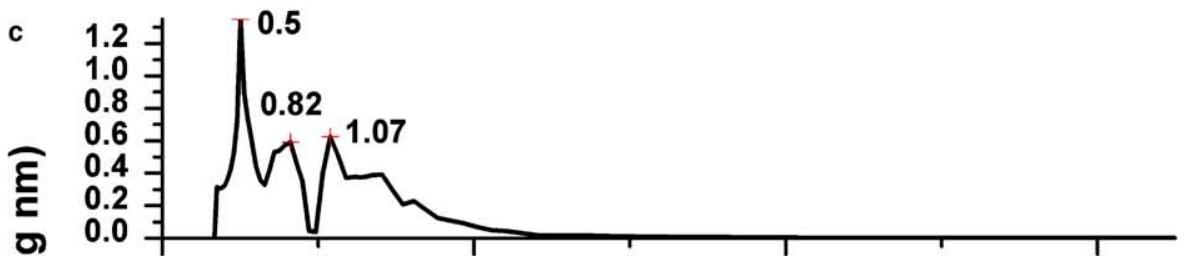

\section{2}

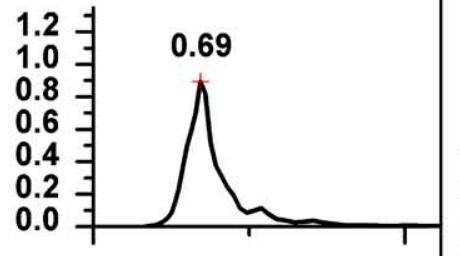

e

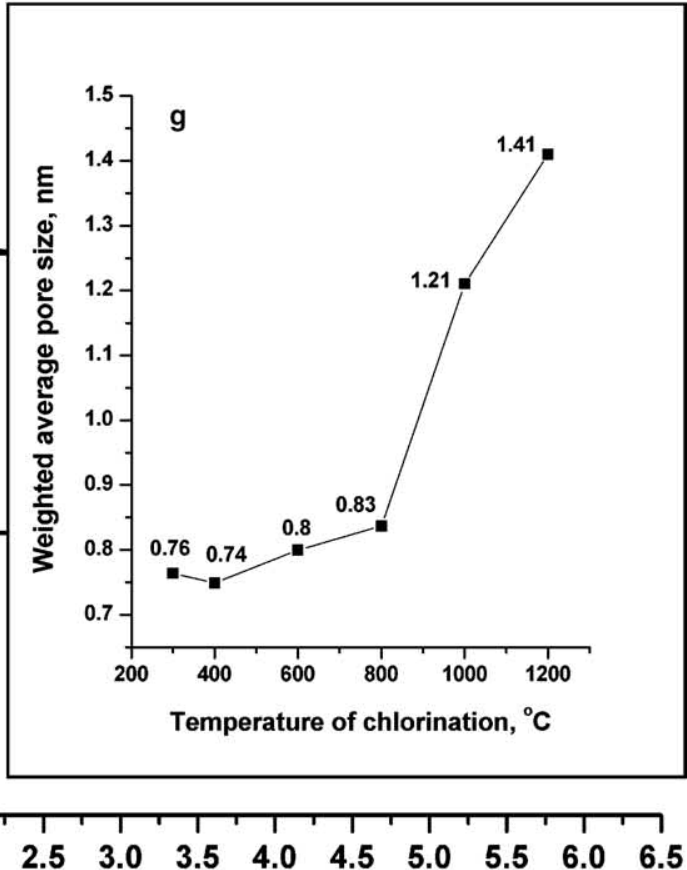

$\mathbf{f}$

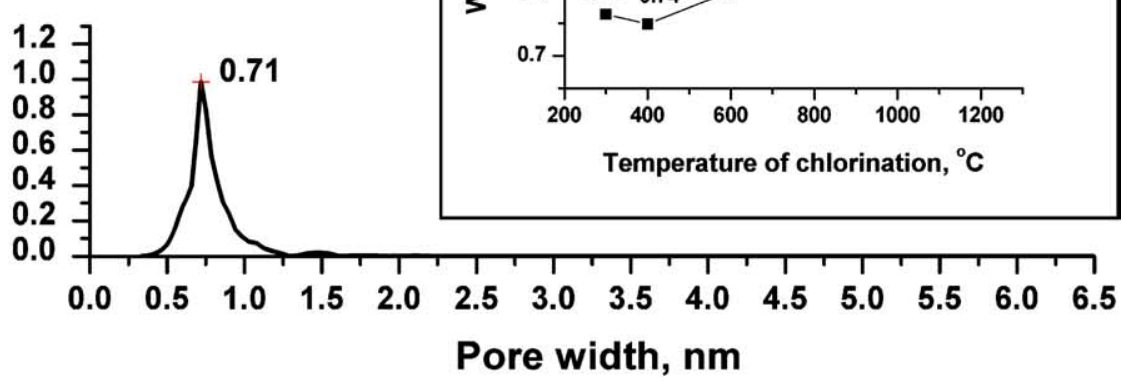

Fig. 7. Pore size distributions for $\mathrm{CDC}$ derived from $\mathrm{ZrC}$ at temperatures of (a) $1200{ }^{\circ} \mathrm{C}$, (b) $1000{ }^{\circ} \mathrm{C}$, (c) $800{ }^{\circ} \mathrm{C}$, (d) $600{ }^{\circ} \mathrm{C}$, (e) $400{ }^{\circ} \mathrm{C}$ and (f) $300^{\circ} \mathrm{C}$. Distributions were calculated for argon adsorption at liquid nitrogen temperature using NLDFT method; (g) $D_{0}$ (weighted average pore size) for $\mathrm{CDC}$ derived from $\mathrm{ZrC}$ at various temperatures. 
A semilogarithmic scale plot of the argon isotherms 250 in Fig. 6b allows one to differentiate between the sorp251 tion behaviors of the samples at low pressures. The $252800{ }^{\circ} \mathrm{C} \mathrm{ZrC}-\mathrm{CDC}$ sample adsorbs more $\mathrm{Ar}$ at a relative 253 pressure between $10^{-6}$ and $10^{-5}$ than ZrC-CDC pre254 pared at any other temperature suggesting that this 255 material has smaller pores than any other $\mathrm{ZrC}-\mathrm{CDC}$ 256 sample synthesized. Similarly, the $600{ }^{\circ} \mathrm{C}$ sample possess 257 pores larger than that of the $800{ }^{\circ} \mathrm{C}$ sample but smaller 258 than that of the other CDCs.

259 The SSA increased with chlorination temperature 260 from $\sim 500 \mathrm{~m}^{2} / \mathrm{g}$ at $300{ }^{\circ} \mathrm{C}$ to a maximum of $261 \sim 1900 \mathrm{~m}^{2} / \mathrm{g}$ at $1200{ }^{\circ} \mathrm{C}$ (Fig. $7 \mathrm{~b}$ ). The total pore volume 262 also showed gradual increase from $\sim 0.2 \mathrm{cc} / \mathrm{g}$ at $300^{\circ} \mathrm{C}$ 263 to over $0.9 \mathrm{cc} / \mathrm{g}$ at $120{ }^{\circ} \mathrm{C}$. The high values of pore vol264 ume achieved at high temperature (higher than the the265 oretical pore volume of $0.86 \mathrm{cc} / \mathrm{g}$ ) indicates partial 266 etching of carbon due to uncontrolled oxidation by 267 traces of oxygen or formation of $\mathrm{CCl}_{4}$. Interestingly, 268 the volume of micropores did not show significant 269 changes at temperatures above $600^{\circ} \mathrm{C}$ whereas the mes270 oporous volume increased significantly from less than $2710.04 \mathrm{cc} / \mathrm{g}$ at $300{ }^{\circ} \mathrm{C}$ to $0.46 \mathrm{cc} / \mathrm{g}$ at $1200^{\circ} \mathrm{C}$.

272 Fig. 8 shows PSDs of CDCs calculated using the 273 NLDFT method assuming slit shaped pores. Although 274 the real shape of the pores is not known, the slit pore 275 assumption seemed reasonable as previously produced 276 CDC derived from $\mathrm{Ti}_{3} \mathrm{SiC}_{2}$ showed slit shaped pores 277 according to the small angle X-ray scattering analysis 278 [3]. In contrast to classical thermodynamic methods 279 for calculation of PSDs, the NLDFT method is based

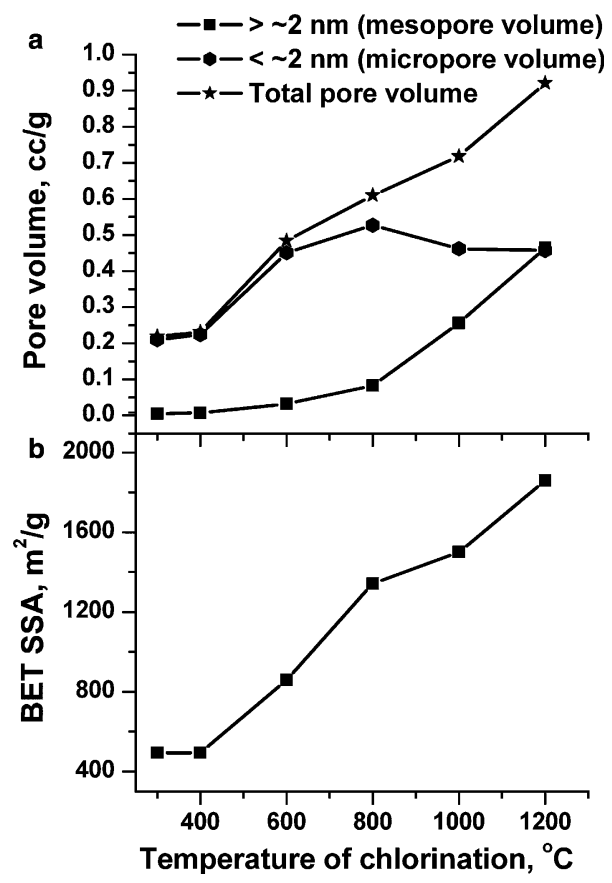

Fig. 8. Results of Ar sorption analysis of CDC-ZrC. (a) Pore volume and (b) BET SSA as a function of the temperatures of chlorination. on a statistical mechanics model, and calculations de- 280 pend on the absorbate-absorbent system. The statistical mechanical model used in NLDFT can be described as the best fit obtained by comparing the theoretical isotherms for argon sorption on carbon to the experimental data. The filling of micropores occurs in a continuous way whereas the filling of mesopores occurs by pore condensation, which represents a first order transition from a gas-like state to a liquid-like state. Classical thermodynamic theories like Barrett-Joiner-Halenda (BJH) are based on pore condensation and thus are only applicable to mesopores. Dubinin-Radushkevich (DR), Horvath and Kawazoe (HK), and Saito and Foley (SF) methods are based on continuous pore filling and thus are applicable to micropores only $[11,20]$. For a material having both micropores and mesopores, the above-mentioned methods cannot accurately describe PSDs and thus we took NLDFT as a method of choice for $\mathrm{ZrC}-\mathrm{CDC}$ samples. The PSDs of 300, 400 and $600{ }^{\circ} \mathrm{C}$ samples were narrow with $D_{\mathrm{m}}$ (pore size corresponding to the maximum in PSD) equal to $0.71,0.69$ and $0.57 \mathrm{~nm}$, respectively where as the PSDs of 800 , 1000 and $1200{ }^{\circ} \mathrm{C}$ samples were wide. The weighted average pore size, $D_{0}$ for various chlorination temperatures (Fig. $7 \mathrm{~g}$ ) shows that the pore size increases with chlorination temperature. However, a decrease of $D_{\mathrm{m}}$ with increasing temperature to $800{ }^{\circ} \mathrm{C}$ suggests that pore structure evolves by short range transport of carbon. When a wall between two cells (pores) of equal size shifts a pore of a smaller size and a larger pore appear. This can explain the transition from a narrow PSD at $300{ }^{\circ} \mathrm{C}$ to a wide PSD at $600^{\circ} \mathrm{C}$.

\section{Discussion}

At low synthesis temperatures, the diffusion of carbon is slow and the morphology of the carbon network formed is expected to be close to the distribution of carbon atoms in the initial carbide structure. As discussed, a porosity of $66 \%$ was expected for the $\mathrm{ZrC}-\mathrm{CDC}$ synthesized. The low SSA in samples produced at low temperature showed that some pores might be blocked by $\mathrm{Cl}_{2}$ and $\mathrm{ZrCl}_{4}$ remaining in the CDC.

Similar to what we observed in other studies [3], structure of porous amorphous CDC showed small pores and narrow PSDs. Such CDCs are generally synthesized at low temperatures (below $600{ }^{\circ} \mathrm{C}$ in the present case). As the temperature increased to $800^{\circ} \mathrm{C}$ and above, the ordering of amorphous carbon took place, as was evident from Raman and TEM analysis, and PSDs widened. The formation of multi-layer graphitic structures at higher temperatures resulted in the increase of the weighed average pore size $\left(D_{0}\right)$. Although loss of carbon atoms (due to the accidental oxidation or the formation of gaseous $\mathrm{CCl}_{4}$ ) or incomplete removal of 


\section{Conclusions} $1200{ }^{\circ} \mathrm{C}$. CDC. chlorine or chlorides may alter the obtained PSD, the discussed dependence of $D_{0}$ is accurate and was observed in all of our studies. The previously discussed increase in mesoporous volume at higher temperatures can be explained by the growth of graphitic ribbons observed by TEM. Ar sorption analysis of $\mathrm{ZrC}-\mathrm{CDC}$ samples showed that the SSA increased with temperature and the corresponding Raman and XRD analysis indicated that ordering of carbon is not because of densification. The increase of SSA with temperature also indicates that most of the pores formed in the CDC at high temperature are open and large enough to be accessible to Ar. The absence of a strong and narrow graphitic peak in Raman spectra indicated that the formed ribbons are highly defective (turbostratic) and thus may adsorb more Ar than thin graphite sheets of comparable wall thickness. The surface area of CDC increases with temperature and reaches $>2000 \mathrm{~m}^{2} / \mathrm{g}$ at

In comparison to $\mathrm{CDCs}$ produced from $\mathrm{B}_{4} \mathrm{C}[4]$ and $\mathrm{Ti}_{3} \mathrm{SiC}_{2}$ [3], whore PSDs do not change appreciably in $200-1200{ }^{\circ} \mathrm{C}$ range, CDC produced from $\mathrm{ZrC}$ can have both narrowly distributed micropores and mesopores depending upon the temperature of synthesis. However, the PSD is significantly broader than in case of SiC-

$\mathrm{ZrC}$-CDC produced at low temperature can be an excellent candidate for gas storage and molecular sieves, while $\mathrm{ZrC}-\mathrm{CDC}$ produced at higher temperatures ( $800{ }^{\circ} \mathrm{C}$ and above) may find applications in sorbents, batteries and supercapacitors.

Highly porous carbon was synthesized by chlorination of $\mathrm{ZrC}$ at different temperatures. Thermodynamic analysis predicts formation of $\mathrm{CCl}_{4}$ below $250-400{ }^{\circ} \mathrm{C}$, depending on amount of chlorine in the system. One mole of carbon and $\mathrm{ZrCl}_{4}$ are predicted above $400{ }^{\circ} \mathrm{C}$. XRD, micro-Raman spectroscopy, and TEM showed that the carbon was amorphous to $600{ }^{\circ} \mathrm{C}, 2-3$ layer graphite ribbons were observed at higher temperatures. Argon sorption measurements show that the porosity of the CDCs depends on the chlorination temperature. At low temperatures (below $600{ }^{\circ} \mathrm{C}$ ), the material contained small pores with a narrow PSD whereas at high temperature (above $1000{ }^{\circ} \mathrm{C}$ ), the material contained larger pores with broad PSD. In comparison to CDCs produced from $\mathrm{B}_{4} \mathrm{C}$ [4], $\mathrm{Fe}_{3} \mathrm{C}$ [17] and $\mathrm{Ti}_{3} \mathrm{SiC}_{2}$ [3], the $\mathrm{ZrC}-\mathrm{CDC}$ shows a lower degree of ordering at high temperatures. In comparison to $\mathrm{CDCs}$ produced from $\mathrm{B}_{4} \mathrm{C}$ [4] and $\mathrm{Ti}_{3} \mathrm{SiC}_{2}$ [3], whose PSDs do not change appreciably in $200-1000^{\circ} \mathrm{C}$ range, $\mathrm{CDCs}$ produced from $\mathrm{ZrC}$ can have both narrowly distributed micropores and mesopores depending upon the temperature of synthesis. However, the PSD is significantly broader than in case of $\mathrm{SiC}-\mathrm{CDC}$.

\section{Acknowledgments}

This work was supported in part by Arkema Inc. The purchase of the Raman spectrometer was supported by NSF grants DMR-0115546 and BES-0216343. HRTEM and XRD were performed in the Regional Materials Characterization Facility at the University of Pennsylvania.

\section{References}

[1] F. Schuth, S.W.K. Sing, J. Weitkamp, Handbook of Porous Solids, 3, WILEY-VCH, 2002.

[2] A. Nikitin, Y. Gogotsi, in: H.S. Nalwa (Ed.), Nanostructured Carbide-Derived Carbon (CDC), Encyclopedia of Nanoscience and Nanotechnology, vol. 7, American Scientific Publishers, CA, 2003, p. 553.

[3] Y. Gogotsi, A. Nikitin, H. Ye, W. Zhou, J.E. Fischer, B. Yi, H.C. Foley, M.W. Barsoum, Nat. Mater. 2 (2003) 591.

[4] R.K. Dash, A. Nikitin, Y. Gogotsi, Micropor. Mesopor. Mater. 72 (2004) 203.

[5] H.O. Pierson, Handbook of Refractory Carbides and Nitrides, William Andrew Publishing/Noyes, 1996.

[6] Y. Gogotsi, V.L. Kuznetsov, G.N. Yushin, A. Nikitin, A.V. Okotrub, A.I. Romanenko, A.I. Boronin, E. Pozhetnov, Carbon (2005).

[7] V.P. Orekhov, G.V. Seryakov, A.N. Zelikman, T.M. Starobina, T.I. Kahzanova, K.V. Petrova, P.M. Sverchkov, J. Appl. Chem. USSR 42 (1969) 230.

[8] S. Brunauer, P. Emmett, E. Teller, J. Am. Chem. Soc. 60 (1938) 309.

[9] S.J. Gregg, K.S.W. Sing, Adsorption, Surface Area and Porosity, Academic Press, London, 1982.

[10] S. Lowell, J.E. Schields, Powder Surface Area and Porosity, New York, 1998.

[11] P.I. Ravikovitch, A.V. Neimark, Colloids Surf. 187-188 (2001) 11.

[12] R.J. Nemanich, S.A. Solin, Phys. Rev. B 20 (1979) 392.

[13] R.P. Vidano, D.B. Fishbach, L.J. Willis, T.M. Loehr, Solid State Commun. 39 (1981) 341.

[14] R.J. Nemanich, G. Lukovsky, S.A. Solin, in: M. Balkanski (Ed.), Proc. Int. Conf. Lattice Dyn., Flammarion Press, Paris, 1975, p. 619.

[15] F. Tuinstra, J.L. Koenig, J. Chem. Phys. 53 (1970) 1126.

[16] C. Thomsen, S. Reich, Phys. Rev. Lett. 85 (2000) 5214.

[17] S. Dimovski, A. Nikitin, H. Ye, Y. Gogotsi, J. Mater. Chem 14 (2003) 238

[18] H. Takikawa, R. Miyano, M. Yatsuki, T. Sakakibara, Jpn. J. Appl. Phys. 37 (1998) L187.

[19] P.A. Webb, C. Orr, Analytical Methods in Fine Particle Technology, Micromeritics Instrument Corporation (1997).

[20] J. Jagiello, M. Thommes, Carbon 42 (2004) 1227.
388 